\title{
Mobile information systems for the private everyday life
}

\author{
Oliver Bohl, Shakib Manouchehri and Udo Winand \\ University of Kassel, Kassel, Germany \\ E-mail: \{bohl, manouchehri, winand $\} @$ wirtschaft.uni-kassel.de
}

\begin{abstract}
Despite the high penetration of the private sector in mobile devices, only few applications and services based on mobile technologies are used, and those are rather trivial. This article suggests an approach for the identification of alternatives for the support of processes of everyday life by establishing services based on mobile applications, mobile devices and infrastructures for mobile dispositions. Therefore, a framework for the identification, as well as criteria for the analysis of potential fields of application is discussed. Exemplary benchmarks for selected basic processes in private everyday life visualise the suggested framework, which can be adapted for individual methodical analyses.
\end{abstract}

Keywords: Mobile services, mobile information systems, strategies for the creation of mobile services, private everyday life

\section{Introduction}

Mobile miniaturised devices and services offering an elevated level of mobility are expected to penetrate business environments and private households. This also applies to such private households, which have not been connected to the (stationary) Internet, but now have access to similar services for the first time. This situation can be characterized as a new level of the pervasiveness of Information and Communication Technologies (ICT) in the private home. In 1996, VENKATESH pointed out that "many of the traditional institutions with which families (and the general public) deal on a daily basis have adopted new technologies as part of their normal routine. In work environments, schools, airports, shopping malls, supermarkets and banks, all kinds of everyday activities are now performed through computer-based technologies." [36] For the mobile service industry, the current situation can be described as following: Wireless data transmitting technologies like WLAN, Bluetooth, GSM and UMTS allow the location- and time-independent use of information, while at the same time the penetration of private households, in powerful devices to use such services, increases. Nevertheless, the sales of mobile applications and services beyond telephone and SMS are disappointing, when compared to the internet services that so drastically changed our lives in the last 10 years [31].

It is of high importance to differentiate between the private and the business life, since huge discrepancies exist between them. It can be observed, that while in business surroundings, more and more mobile services have been established [13], the penetration of the private sector in mobile services is, despite a couple of commercial successes and some comprehensive services, such as i-mode in Japan or mobile television in Korea, limited to sales of ring tones, games for mobile phones and similar offers of low value in most regions [38]. In most regions there is a tremendous gap between the amount of users of stationary Internet-based services (electronic services, e-services) and the users of mobile technologies 
(mobile services, m-services). Also, due to the evolving needs of private customers for communicating and exchanging information and with 24/7-access, there is unquestionably a strong need to identify other promising areas [6]. After the initial disappointment, this seems to be the right moment to take a better look at the customer's needs, concerning mobile technology.

Regarding the situation described above, there is an obvious requirement to establish common methods for the creation of useful and acceptable services for private customers. This need is supported by the following statement: "Don't assume that what the technology can do in the household is the same as what the household wants to do with the technology" [36]. Therefore, a main objective of this article is to develop a methodical framework for the analysis of processes in settings of private everyday life. This framework will allow the assessment of alternatives to support these processes with mobile services. Thus, it facilitates the creation of recommendations for developing, launching and establishing complex services in private settings.

Since the users' experience with mobile services, as well as with so called complex services, a combination of mobile, stationary e-services, and also services offered by ubiquitous technologies, is very limited to almost non-existent, we refrained from performing empirical research to illustrate the consumers' requirements and needs. Instead, we focus on the development of a methodical approach, which is based on exemplary characteristics of processes in private everyday life. These processes will be combined and judged in connection with specific possibilities regarding the support of mobility offered by Internet-based services and especially, by mobile applications, mobile devices and mobile infrastructures.

\section{Related work}

As mobile technologies are the next step towards the ubiquity of ICT-based services, the mobilization of formerly stationary Internet services is evolving into an important research issue. This paper is connected to a portfolio of research activities. Some of the most prominent ones will be introduced below.

First detailed and pointed research activities within the field of ICT in the private everyday life were conducted in the 1980s. These studies included longitudinal surveys, regional/national cross sectional surveys and ethnographic field studies of home computer users, to identify barriers to the technological diffusion in private households. These barriers were later figured out though interactions between the social space in which the behaviour of private users occur, and the technological space in which ICT are embedded [36]. While these first approaches were focussed primarily on the adoption of stationary ICT, the wide diffusion of mobile technologies, offers enhanced opportunities as well as it causes extended requirements. Efforts towards this aim correlate with current research activities in academia and industry [37], as well as with the blurring and convergence of the formerly separated sectors of private everyday life and business life. For example, the discipline of information systems explicitly has dealt with the private sector for a few years now, while before, only enterprise application systems had been focussed. This leads to a situation described by MONK: "While many of the concepts and methods developed in the work context will transfer to home use, there is still a lot research to do before we gain the same level of understanding that is reflected in current standards and methods for designing graphical user interfaces for office products" [19]. While this is the case for the design of user interfaces, it seems to be even more crucial for the development of innovative mobile services.

This is critical if one regards the situation described by PHAM, SCHNEIDER and GOOSE, which conclude that the future use of computers is driven by a phenomenal growth, as well as a rising demand. This 
will lead to scenarios in which nomadic users will access Internet content anywhere at any time by using technologies of mobile and ubiquitous computing [27]. In publications on the wireless future predominantly technological requirements are elaborated and specified [25]. This is a main reason why most research activities lack on further discussions of end-user issues, which can contrary be declared as elementary for offering services to private households. Regarding for instance the user acceptance, it is advisable to regard the existing services being offered. The stationary Internet services arose as new forms of ICT-supported services since the 1990s; they are often named e-services and are used with a regular Internet access by cable [6]. Meanwhile these services normally hold an added value for the users. They also usually have a high grade of acceptance. An arising and significant extension of appropriated services is the mobile use of so far pure stationary e-services. KEMPER and WOLF describe the current trend as follows: “..., since innovative technologies like GPRS, HSCDS, UMTS and Bluetooth are increasingly achieving readiness for market, it is assumed that, in the near future, more and more mobile applications will be developed that provide services complementary and comparable to fixed-line e-commerce" [11]. In most of such scenarios mobile technologies are offering a multitude of opportunities and chances to create novel kinds of ICT-based services for several private user groups.

Preliminary research has been already conducted on the adoption of mobile services within private households [24,25]. A core result of most research activities is that applications from the private environment which have been linked to stationary computer systems as well as the ones being linked to home entertainment systems should be used in innovative mobile scenarios. This can be realized by extending their interfaces and by extending their possible fields of application. In this regard, some frameworks already exist, which are describing the needed adaptation from a technological point of view. Nevertheless most of these approaches suffer the lack of inclusion of the users needs [25]. Rather current research results present preliminary results of how to design the presentation layer of the mobile service, while obtaining/migrating the functional logic and the usability of the services. These approaches should be enhanced by focussing on the needs of the end users and on the possibility mobile technology offers $[28,30]$.

Thus, within this paper user-oriented issues will be discussed, such as the migration of services of the first generation of ICT-based applications (with unintuitive text-based interfaces) to modern PCs (with multimedia-enabled GUIs). It is important to analyse problems of how to migrate services that are optimized for traditional stationary PCs in a way that they can be used on modern mobile devices. By doing so, the user behaviours have to be adapted, while maintaining user experience and the users' knowledge on how to use traditional (e-) services. This concept of migration is characterized by the transition of one system to a new improved one with the aim to keep (some) heritage elements. Migration promises potentials for an increased acceptability for the implementation of "new" or "better enhanced" applications [21].

Despite the interesting fields illustrated above, this article focuses on a specific area of the broad field of bringing mobile services to private households in an efficient and effective manner. As an approach, to provide a structured framing of future developments, the following chapters will develop a framework for the methodical evaluation of application fields for mobile services in the private everyday life.

\section{Classification of mobile private everyday life}

As illustrated above the advancements of ICT have enormous impacts on private settings, as well as users in private settings, have impact on the further development and distribution of ICT, in general and mobile services, in particular [37]. Private user groups can utilize the offered services to make their 
lives easier, more enjoyable and more convenient, and maybe even safer as well. MUNDORF defines services as "functions performed by others outside or inside the home. Technological changes allow us to achieve some of these goals through technologies and substitute or complement services performed by others" [22]. To reach this goal and to identify options to support processes of private everyday life by using combinations of Internet technologies, mobile technologies and ubiquitous technologies, it is necessary to describe the theoretical context first. Since the provision of mobile services is focussed in this article, it is necessary to narrow down our understanding of mobility at first [6].

Many research disciplines, like for instance demography, sociology, geography, psychology, economics and communication sciences deal with aspects of mobility [40]. As a result, the concept is used in different contexts with different meanings [38]. A simplified classification of the term mobility can be based on its basic characteristics. An important distinction is the differentiation in physical mobility and in a more abstract type of mobility. Whereas physical mobility means a change of the location of persons/objects, however, mobility can also be enabled by movements in more abstract ranges. An example for such specifications of abstract mobility is social mobility, which refers to the ability of individuals to move between social levels within a society [17]. Mobility can also be distinguished in mobility in the context of a spatial movement of persons or other physical objects and so-called virtual mobility. The term virtual mobility is heavily influenced by modern ICT. Therefore, it can be understood as a type of mobility of humans to make new contexts accessible by using ICT in a virtual sense, without necessarily being mobile in a physical sense [40]. In combination, mobility marks a transition to more flexible services by using ICT to reach a spatial decoupling. Data mobility is an example for this kind of mobility. In the development of innovative services in private everyday life, this kind of mobility plays a substantial role [26]. The term "mobility" as used in this article contains both aspects of physical and virtual mobility.

In contrast, only a few definitions of the concept of ICT-supported private everyday life exist [12, 29]. Additionally, only a few notable publications exist in the area of ICT development for private settings $[14,23,36]$. KOLBE explains that the digital data processing of private household covers all infrastructures and applications, which are used by private users for predominantly private motivated purposes [12]. Some common terms which are related to this area are "home information system" [10], "home informatics" [18,32], "home oriented informatics and telematics" [35] as well as "consumer multimedia" [15]. Obviously, the inclusion of mobile technologies lifts the ICT-supported private everyday life to a new level of complexity, since the formerly existing borders of the residence of the user blur. This is in line with existing approaches: In a broad sense, all areas of private life can be merged in the term "private everyday life". This implies that more than just the residence of privacy is characterized; in fact the exclusive commitment for private purposes takes the centre stage. The services and products can be used by all members of a private household [12]. Another related term which is discussed in some publications is "residential customer" [4].

Generally, all kinds of mobility in private contexts using mobile services can be summarised as constitutive elements of mobile private everyday life. Consequently, user mobility as defined above is regarded as a substantial criterion. This kind of mobility is realised by an active and/or passive exchange of information using mobile devices and infrastructures. This might cover almost all processes of everyday live. One can identify the processes of information access, communication, entertainment, buying, habitation, education, agility, health and the management of the household as core processes [12]. The emerging and innovative ways of utilizing ICT-supported services in mobile environments enable private user groups to make extensive use of innovative mobile services within all of these processes. While other mass media, especially television and radio, nowadays and in most regions are used in a 
collective way, e.g. by listing or watching together with the family, mobile devices provide a higher amount of intimacy, privacy and individual availableness. Likewise, the option of ICT to interact actively, represent a significant enhancement compared with the formerly used mass media. Beside these enhanced possibilities, the selling of mobile devices for good values and provider contracts with moderate prices, foster the diffusion of mobile devices.

These factors as well as the incremental convergence, on one hand mobile and stationary technologies and on the other hand the sectors of consumer electronics and ICT, boost the amount of visits of mobile user groups on web pages as well as the usage of mobile services in general. Some prominent examples from Asian regions illustrate impressively, that mobile devices have the potential to be developed towards the primary end device [33]. Thus, the mobile access to formerly only stationary accessible services and data is growing. It is already widely-used in some fields of application as well as in some regions like Japan or South Korea [16]. Some authors already predict that on a global scale the amount of users of the Internet who access the Internet via mobile devices will exceed the amount of users accessing stationary, in the near future. This will lead to innovative usage scenarios. For instance, the aspired increase of mobility in private everyday life holds strong potential for a serious change of social contacts and will also change the ways families interact. Preliminary examples of this alteration will be illustrated and also a method to systematically overcome the required changes will be developed.

\section{Framework for the methodical evaluation of application fields in everyday life}

The framework illustrated is motivated by the elementary need to understand the role mobile devices and mobile technologies can play in future settings of the private everyday life. Therefore firstly the activities of such settings have to be analyzed. On one hand one can regard private households in a holistic fashion but on the other hand one can also combine the underlying activities in meaningful segments [36]. This means that core activities of the private everyday life can be illustrated in a process-oriented way. Nevertheless there are significant differences between private and business-related activities [38]. Thus the activities in private settings are less characterised by logical arrangements, especially in contrast to often well-structured business activities. Rather spontaneous and unstructured activities and processes can be observed [20].

Based on these assumptions this section presents a methodical framework for a systematic identification and evaluation of processes in private everyday life. This framework will allow assessing alternatives to support these processes with mobile services and facilitates the creation of recommendations for developing, launching and establishing complex services in private settings. The framework is based on 6 steps, which are discussed below. For this purpose, activities of private everyday life are identified, especially those in which users are supported by several services. Possible examples of such activities in the private everyday life can be routine activities like for instance shopping, dating, travelling or simply visiting friends and meeting the family. The identified activities will be valued with respect to in their relations to each other by means of a triangle matrix. For doing so various criteria must be requisitioned. The criteria must represent a benefit for the users in their private everyday life. Distance, time-consuming, the ease of payment or the fun connected with the activities can define supporting factors.

In order to show the resemblance of the identified activities and to classify them into new groups, the the cluster analysis method will be used [1,7]. Cluster analysis is a method for the classification of objects with the goal to summarize single objects corresponding to its resemblance regarding the measured variable. Such an analysis should lead to the identification of homogeneous groups [7]. For 

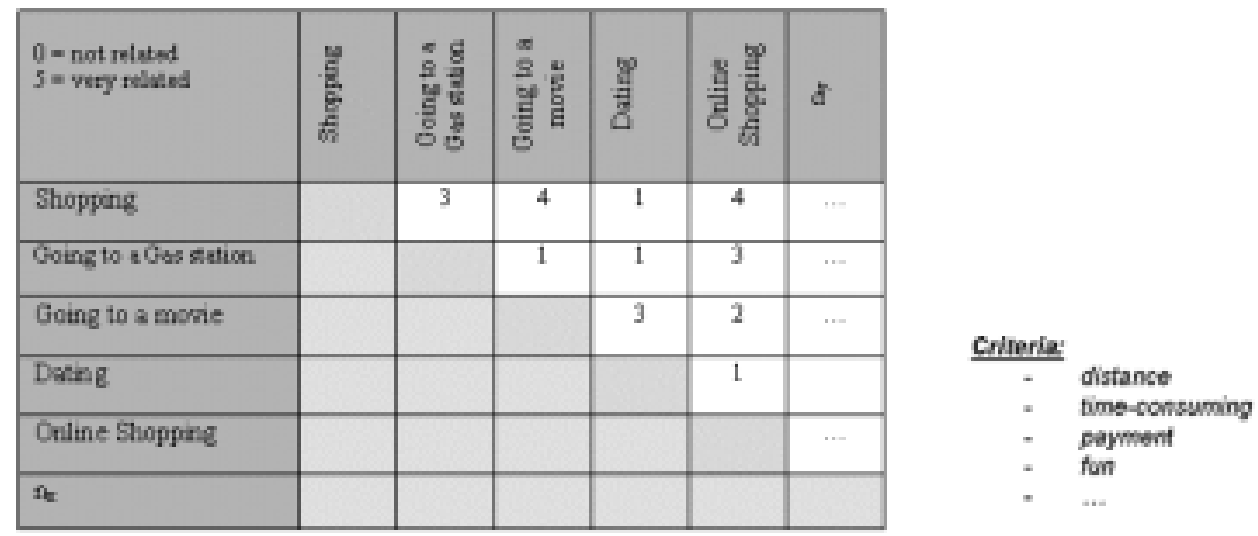

Fig. 1. Evaluation of activities in private everyday life.

the purpose of the proposed framework it is necessary that each activity forms a separate cluster. Thus in the first step it was assumed that for $\mathrm{n}$ activities, $\mathrm{n}$ clusters exist. In the next step objects are identified, which are similar to each other, in order to combine them in a common cluster. The similarity is valued at the same time by its distance to each other. Thus the determination of the point-to-point distances plays a central role. For the new matrix (with n-1 column and lines) the new distances are calculated. The results are shown in Fig. 1.

For calculating the distances, three different procedures exist: The single-link-method, the completelink-method and the average-link method. They differ in the calculation between the clusters. Within this framework the single-link-method was used, which takes the shortest distance to the next neighbours. Thereby it is important that every classified object should at least possess one next neighbour in the cluster. Step 2 and step 3 will be repeated to form homogenous groups. In this context the statements are more certain, the larger the amount of the identified groups is. Within these steps problems with the communication of the statements might emerge [1].

Within the analysis the current situation is described with help of suitable methods and tools, for instance by using and adapting approaches and methods of cluster analyses [1]. Such well-known approaches and methods help to identify and evaluate potential fields of applications, which contain strong potentials for the (mobile) ICT support. Furthermore, first segmentations exist, e.g. SZABÓ distinguishes services for society-related needs in educational applications, telemedicine applications, and governmental applications [34]. Such a classification is too limited for a substantial description of activities in private everyday life. Therefore, a more fundamental approach should be chosen to identify processes in this sector. By analysing private everyday life and highlighting the basic needs of humans in this context, six basic processes were identified [2]: everyday life \& its organisation, mobility \& orientation, knowledge \& entertainment, spare time \& experience, relationship \& contacts, and health \& security. These basic processes are visualized in Fig. 2.

Central needs and important sub-processes can be assigned to the fundamental processes characterised above. For instance it is possible to assign the needs "accessibility" and "individual mobility" to the basic process mobility \& orientation. In turn, these needs can occur in different contexts, e.g. at the gas station, when parking, at the restaurant, in the car, on the bus, during traffic jams or on day trips.

Apart from the identification of processes of private everyday life, even of only exemplary ones, the influence of mobile technologies must be examined in detail. This should be done to enable the 


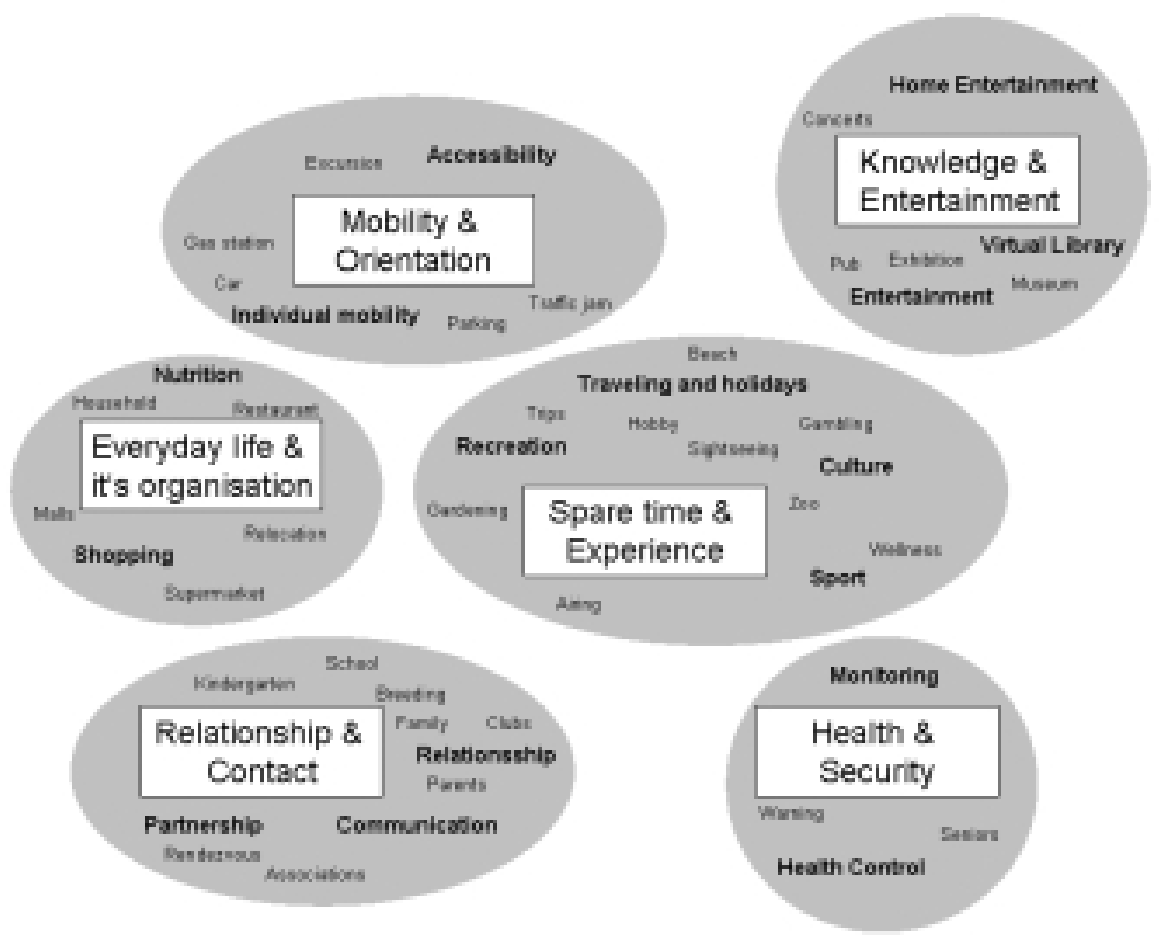

Fig. 2. Basic processes of private everyday life.

identification of their possibilities for the support of the identified basic processes. Based on the potential of mobile technologies, eight criteria can be highlighted as inherent possibilities for the support of mobile services in private everyday life settings [5]:

- A first criterion is represented by the possibility of localisation. It offers possibilities to support the accurate determination where the user physically make use of e.g. GPS-based applications or possibilities modern cellular phone networks like GSM or UTMS offer (cell identification).

- Independence of location represents a second criterion. It supports the communication, the access to, and the posting of information independent of the individual user's physical location.

- Accessibility, as a third criterion, ensures the accessibility by the user. This applies at any time and independent of place. In most developed nations nowadays more than $99 \%$ of all regions have access to mobile infrastructures - which supports the concept of always being connected [31].

- Personalisation as a fourth criterion facilitates individualised services by offering options for a unique and well-defined identification, e.g. by using the integrated SIM card.

- The fifth criterion, context specificity, offers opportunities to receive (even individualised) offers fitting with the present context, e.g. the current activity, the personal interests or the time of day.

- Enhanced comfort and convenience as a sixth criterion is provided by easy to use and faster access to services. The penetration of most societies with mobile devices is much higher than the penetration with PCs.

- Cost-effectiveness as a seventh criterion serves the potential design of the services to meet their intended use. Since the costs for mobile communication are decreasing an adjustment with traditional methods can be predicted. 


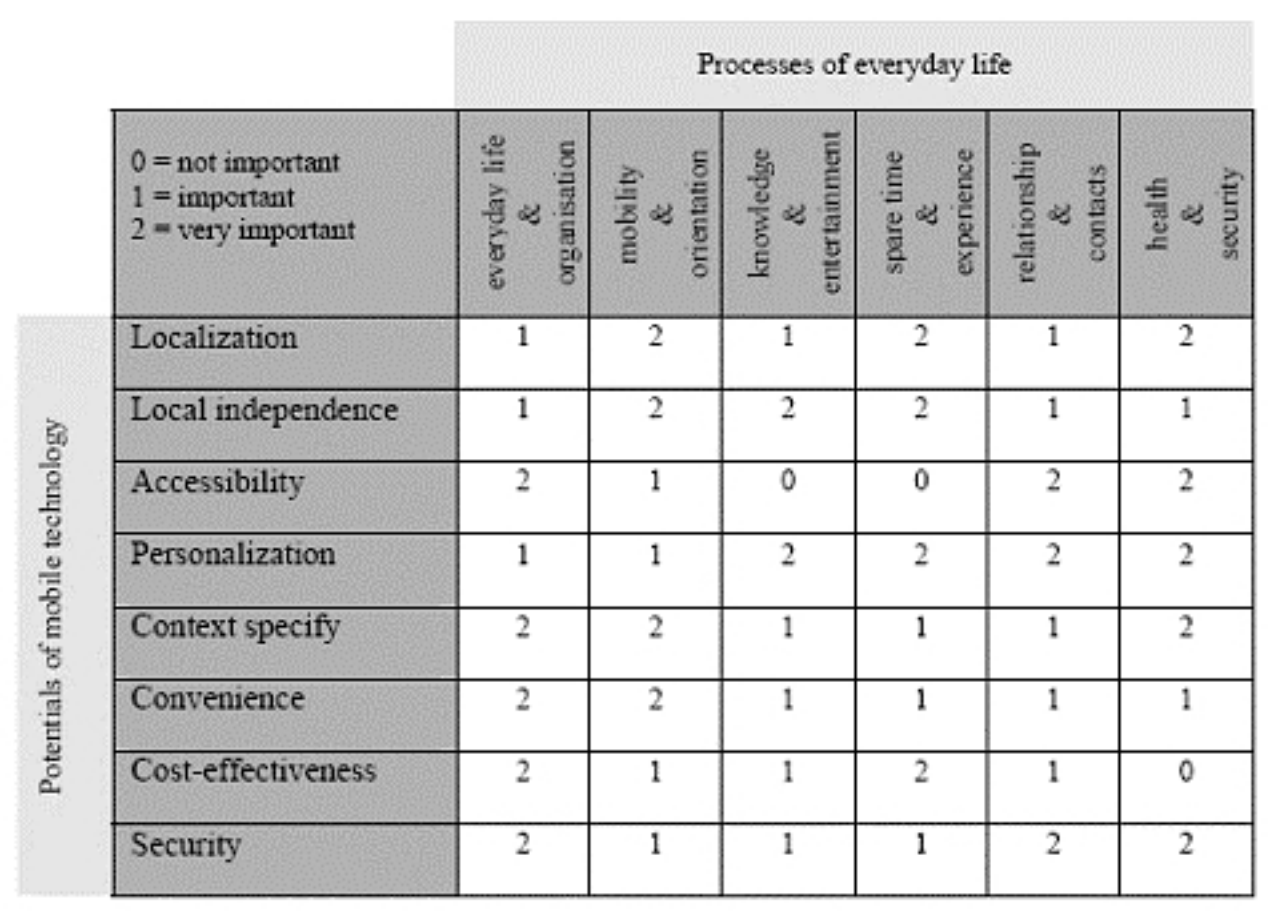

Fig. 3. Exemplary benchmark.

- As an eighth criterion, security means to ensure the explicit identification of the user, e.g. by SIM card. It even is possible to offer an equal or even higher security than stationary PCs can provide.

In order to describe possibilities of specific mobile services to support several processes of the private everyday life optimally, these processes have to be measured with the potentials of mobile services. Such a comparison can be realized in the context of a plain value benefit analysis [1,9]. Within such an analysis the potentials described above are analysed concerning the degree of their support of the basic processes. The following Fig. 3 clarifies this procedure in an exemplary way [2].

Figure 4 represents a detailed, while still exemplary benchmark based on the potentials presented above. The illustrated results refer to an estimation of the values for the basic process mobility \& orientation. The criterion of localisation seems to be of high importance for this group of processes. This is especially the case because of the potentials of localisation and with regards to scenarios in which situation-specific orientation in foreign environments is needed. The criterion of cost-effectiveness seems to be of minor importance. This rating can be justified with the potentially increased willingness to pay for mobile services. By summarising the criteria's previous weighting and by concerning the identified processes, these processes can be put in a ranked order. This ranking can be extended by incorporating further, more specific characteristics, for instance by including a segmentation of the target group with criteria like age group or individual relationships [2].

In order to create a comparison, Fig. 5 illustrates the estimation of the values for the basic process spare time \& experiences. The criteria localization, local independence, cost-effectiveness, and personalization play important roles for this process, while the criterion of accessibility has a much lower importance. Maybe some users might prefer local independence to follow spare time activities from everywhere as 


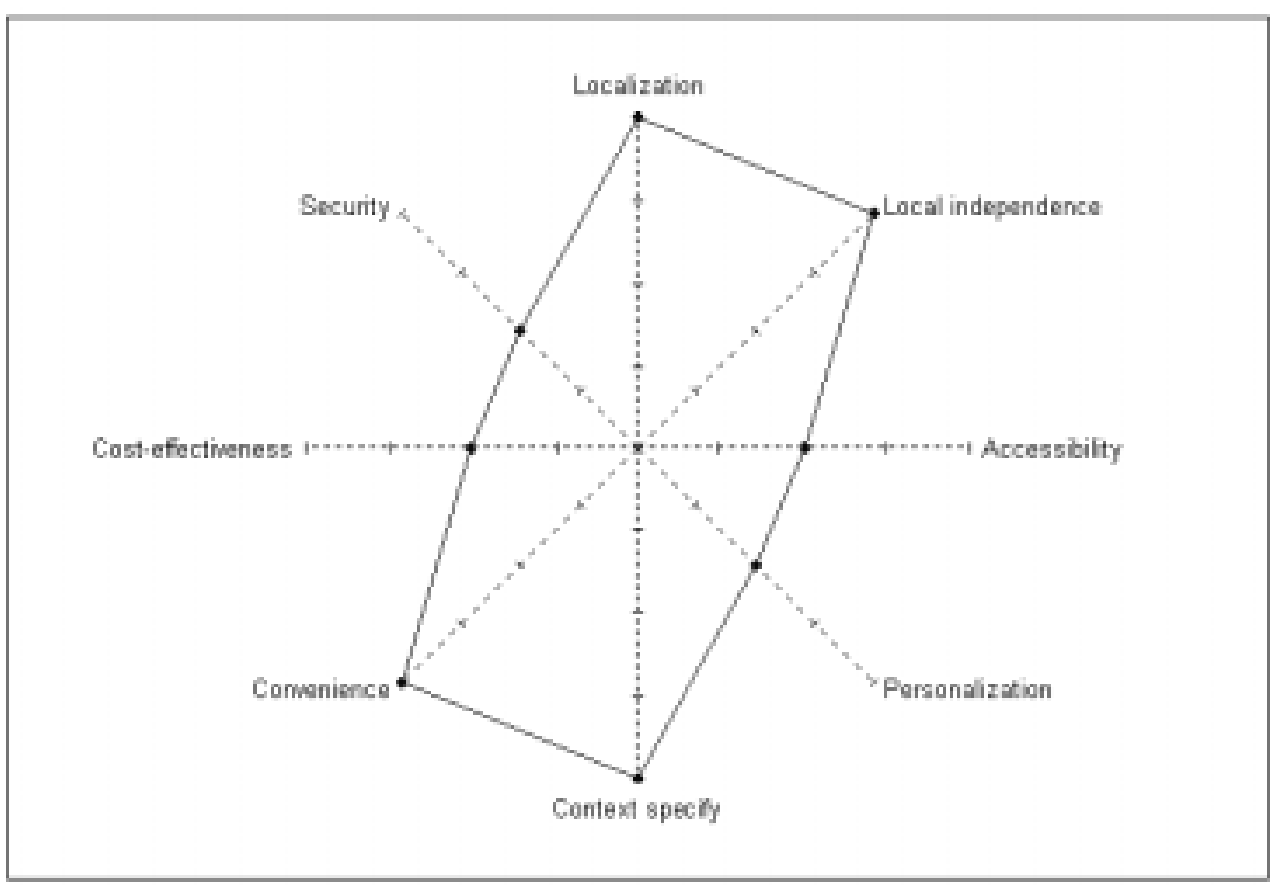

Fig. 4. Estimation of the basic process mobility \& orientation.

well. Also the services offered must be designed in an economical way. The criteria localisation and personalization take a supporting function of higher importance as well.

In this context, the example given above clarifies that, as a result of the used approach to benchmark the intensity of the potentials in specific fields of application, chances of establishing successful mobile services arise. Built on such a combination of the processes of private everyday life with the potentials of mobile services, it seems possible to identify promising domains of application for specific, individual mobile services.

It becomes clear that by using such an approach and by incorporating the needs of the users in the framework, possibilities for establishing mobile services in private contexts can be identified in a target-oriented way. By applying a methodical and substantiated procedure, mobile services for private everyday life can be developed more efficiently. This is relevant, because besides a specific degree of (economical) security for the corporate supplier, the services can be implemented in a more flexible and contemporary manner. The potentials of mobile services can be judged in advance and in the context of specific processes of private everyday life in particular. Beyond that they can also be rated regarding their potential of creating added value on the users' side.

\section{Case studies to highlight the proposed method}

At this point, the article focuses on two examples, which illustrate the emerging possibilities mobile technologies offer for their applicability in the private everyday life. The aim of these case studies is to analyze the above identified sectors of application in a prototypical way. Thus it is possible to evaluate the sectors which were characterized as the most important ones. From there two prototypes were developed for illustrating potentials of supporting end users in specific processes. 


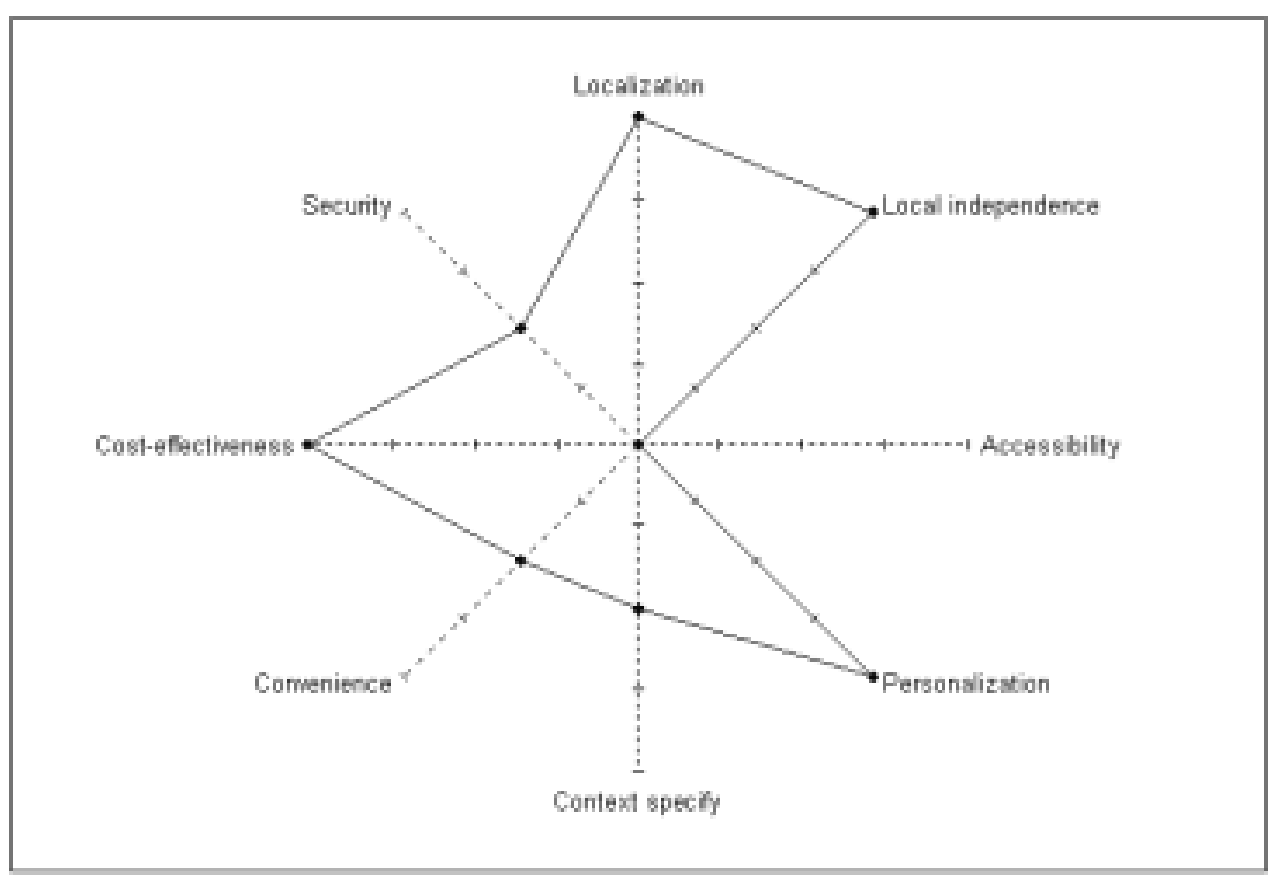

Fig. 5. Estimation for the basic process spare time \& experiences.

\subsection{Case Study I: Imopo}

The first case study deals with imopo, which is a full service provider for individual mobility. It offers a combination of various complex services which comprises, among other things, services like travel agency, booking systems, car rental, and a formalised hitchhiking service. Furthermore, imopo is a partner of a considerable number of companies and provides special rates by using existing services. The services of imopo can be used via the Internet, connected car driver support systems, Internet terminals, and various mobile devices like PDAs or cell phones. A typical usage scenario is described in the following [3]:

Michael, 56, is a salesman and a member of imopo. Today, he is on his way from Berlin to Munich. During his ride, Michael thinks about picking up one or two passengers. So he logs on to imopo by using his Internet-compatible driver support system and places his offer for a ride by voice entry. Using information like speed and road conditions, the satellite-supported IT system of imopo calculates his route and starts searching for suitable travelling companions. Sara, 21, is a student of business management in Kassel. On impulse, she has decided to make a trip to London to visit friends today. With her cell phone she logs on to the imopo mobile portal and submits her request for mobility services. Based on her profile, imopo offers Sara a set of flight connections from airports close to her city. To reach the airport Sara can choose between train connections, public transportation, rental cars or search for a ride via a hitchhiking service. After the confirmation of her search criteria, she receives fitting search results which are ranked according to her individual profile. Due to this profile Sara often prefers reasonably priced ways to travel.

Thus, a combination of ways to reach the airport and favourable flight rates is offered. For the requested route the formalised hitchhiking service is ranked as being the cheapest way to reach Frankfurt airport, 


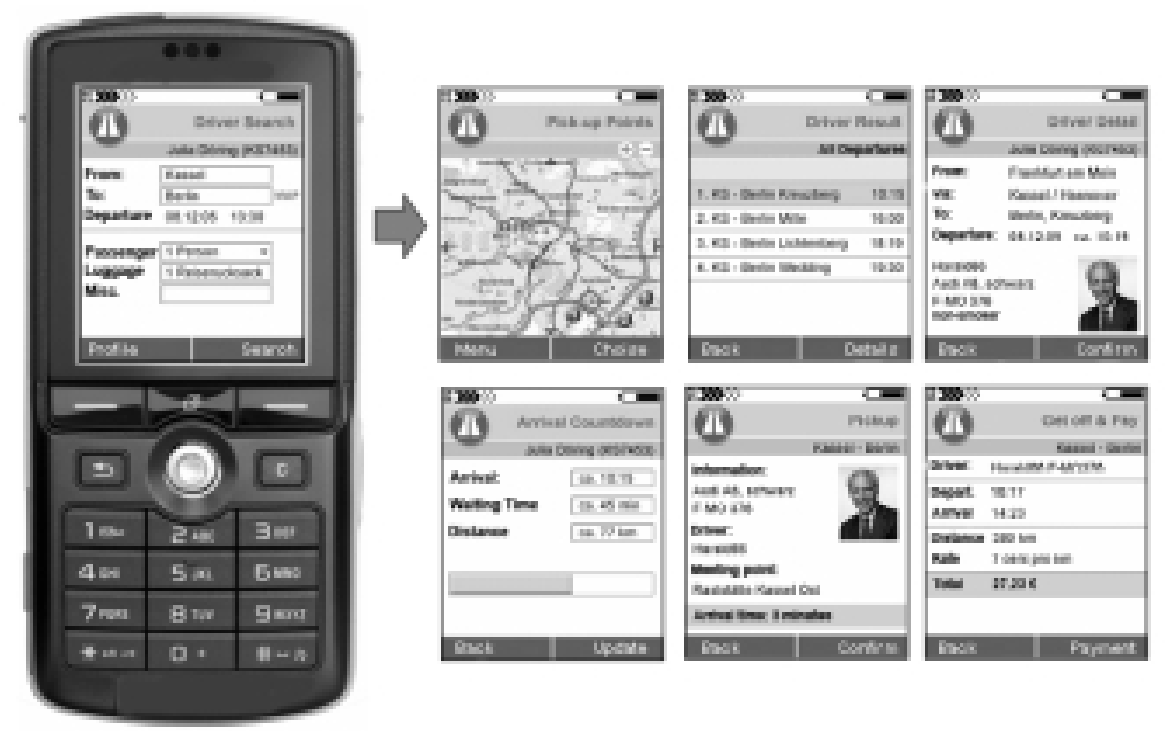

Fig. 6. Imopo on a cell phone.

where flights of a non-frills airline are offered last minute and only for imopo users. Sara decides to book such a flight and to have a closer look on the opportunities the hitchhiking service offers. After confirming her flight to London, she receives a list of different offers. These are sorted by categories like departure and arrival time, smoker or non-smoker, and the gender of the driver. The named stages are illustrated in Fig. 6.

Sara prefers non-smoking drivers. Thus, the ride fitting best with the necessary arrival time is the one Michael is offering. After taking a look at the driver profile, Sara decides to take the ride with Michael. She chooses a suitable pick-up point and confirms her interest in Michaels offer via her cell phone. Michael immediately receives Sara's request through his driver support system. He confirms to take her along. His route is automatically adjusted minimally to reach the arranged pick-up point. Through the confirmation Michael sent, a binding contract of carriage is created within imopo. Using information from Michael's satellite supported driver support system, imopo calculates Michael's time of arrival to be in three hours. Thus the countdown for Michael's arrival at the agreed pick-up point starts automatically on Sara's mobile phone. Now Sara can take her time and comfortably pack her suitcases. After packing she makes her way to the arranged motorway service stop, which is within walking distance of her flat. When Sara and Michael meet, both confirm the beginning of the ride which activates a mileage counter on both devices. The data is transmitted to the imopo portal as well. The two travel towards Frankfurt Airport.

At the same time Tim, 34, another member of imopo, is on the flight LH405 from New York to Frankfurt. Because of technical problems his flight is delayed by three hours. He realises that he is going to miss the last train to Munich today. Via using the Internet access on board, he logs onto the web portal of imopo and tries to check some alternatives for going to Munich immediately after arriving at the Frankfurt Airport. Due to his personal profile imopo offers to rent a car at the airport. Because of having worked and travelled since the early morning, Tim feels tired. Thus he asks for other opportunities to travel. imopo switches to the hitchhiking service and provides a list of rides offered by members on their way to Munich. After taking a look at various offers and refining his search with some preferences, 
e.g. non-smoking drivers and prompt pick-up, Tim decides to ride with Michael, who offers a free seat in his car. He chooses a suitable pick-up point at Terminal II and confirms his interest in Michael's offer. Michael confirms this request immediately. After receiving Michael's agreement, Tim contacts imopo again and receives a list of hotels in Munich. Because imopo customers receive special rates in certain hotels, Tim is able to find an excellent hotel fitting with his budget. When arriving at the Frankfurt Airport, Sara is notified how long the ride with Michael has been so far. The same information is available on Michael's driver support system. Sara pays her share of the costs directly by using her mobile phone. Instantly, Michael is informed of the acceptance of the payment. Tim is already waiting at the airport at the agreed pick-up point and sees Michael arriving. Their shared ride from Frankfurt Airport to Munich begins with the confirmation and activation of the mileage counters. To activate his mileage counter Tim is uses his wireless-connected PDA, on which he can also work on his presentation for the day after.

\subsection{Case Study II: MEG - Mobile Event Guide}

The second case study can be described as a conceptual example of an event guide realized through mobile technologies. The aim is to illustrate some of the most important potentials and restrictions such a service can offer. The world's largest exhibition of contemporary art, the Documenta in Kassel, Germany, was chosen as a scenario for illustrating how a mobile event guide based on contextual as well as on user-created contents would work. Every five years and for the duration of 100 days, this event is spread out across the entire city and takes place in museums and public spaces. The art exhibition attracts around a million visitors over its course, most of whom unaware of what to expect and a lot of them motivated to see as much as possible.

The Mobile Event Guide (MEG) is a context-based mobile application for people visiting large art or other cultural events. It helps users to find their way around such large events quickly and in a targeted way. Based on an evaluation of current contextual-data, a preset user profile, preference records, and continually generated visitor statistics/evaluations, this service provides customized information and services, as well as community communication for users across the entire event. In addition to this, local and urban exhibition-limited ratings, votes, and forums are set up. These include individually customized tours as well as listings of the most important attractions, works of art, and current accompanying events within the local vicinity of the user's current location. It is also important to mention that there is no single day like another and the preferences of experts and art novices could differ extremely. Nevertheless it is possible to publish and automatically evaluate rankings about the most attractive works of art and even to create timing based, weather-based and visitor-number-based route plans. User interfaces of the MEG are shown in Fig. 7.

Such a local and contextual mobile social software solution could change the relationship to art and the way in which it is appreciated - events are enriched by the voice of the crowd. The mass of visitors acts as a counter balance to the opinion of expert art critics. Indeed, visitors are given a voice and an opportunity to influence the interaction. Recommendations and rankings are aggregated and could be retrieved locally. Besides this daily or weekly cluster results can be retrieved. People from Asia or America can see how people of the same age or people from their own regions have rated the artworks. Senior citizens can follow the "taste trail" of teenagers and make the day of their grandchild. Also friends and acquaintances can be identified. Information about whether or not they join the event currently and where they are located could be provided. Guidance systems and directions to facilities can be optimized and information can be sent in a location-related way. All visitors, however, will only be able to submit 

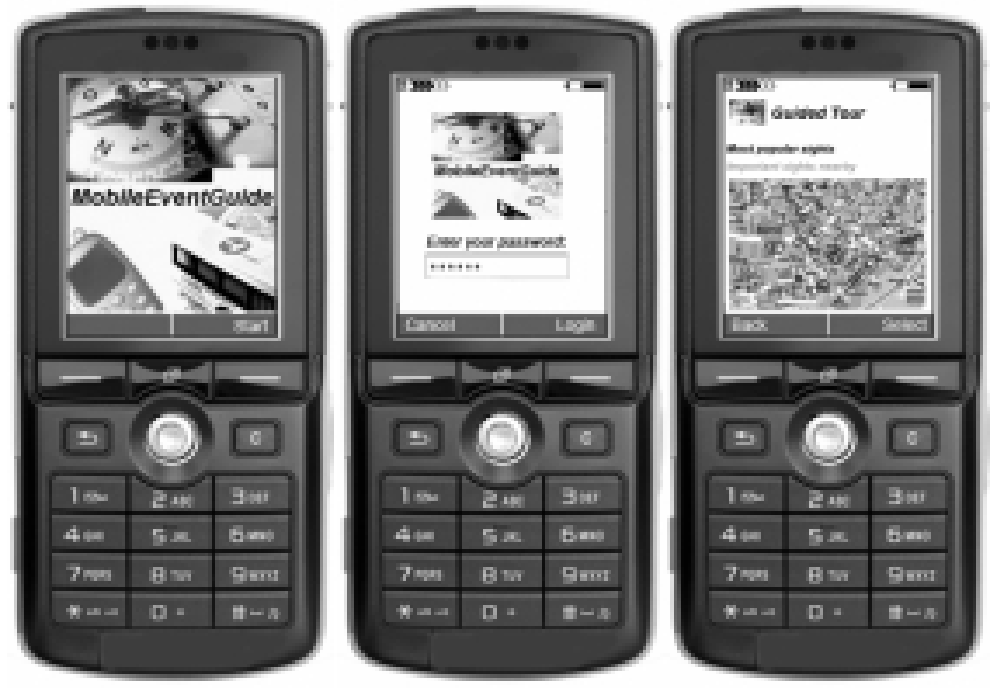

Fig. 7. Screen of the proposed MEG.

a critique when they are actually at the location and have been identified as a visitor. It will be possible to create forums, tips and even new user-generated categories for ratings. Thus the visitors will become part of a local and contextual event.

Services such as MEG will serve in countering this trend in an event-based manner. As far as time, location and space are concerned, events are limited happenings that usually mobilize a large target group. These attributes in particular represent success factors for context-based mobile social software interactions. Dodgeball.com, which sends out a message to users when one of their friends happens to be in the local vicinity, provides a good example of one important future development that will counter the oversupply situation. This example demonstrates that "mobile social software" can be implemented with great success in metropolitan settings. Indeed, such kinds of software serve in creating new worlds of experience and making life in big cities more attractive. Event interaction in local metropolitan spaces, ideally with a lot of assistance from local communities is a core user need which also correlates with the analyses illustrated above.

\section{Evaluation of the framework}

Mobile services could create many value potentials for private users groups: The scenarios described illustrate exemplary potentials that mobile services could offer. These can be split into the eight already identified and defined criteria, which support complex services in settings of private everyday life. For instance, a higher level of cost-effectiveness could be achieved within the described scenario through a better use of resources (e.g. by sharing the car with travel companions) through a higher level of price transparency (e.g. comparison of hotels), and through the market power of large corporations to achieve discounts (e.g. special flights of non-frills airlines for users of specific services). Just like this, it is possible to enable an enhanced comfort and convenience. This can be achieved through the installation of optimising systems (e.g. by including personal preferences, combining different services, and incorporating actual conditions). 


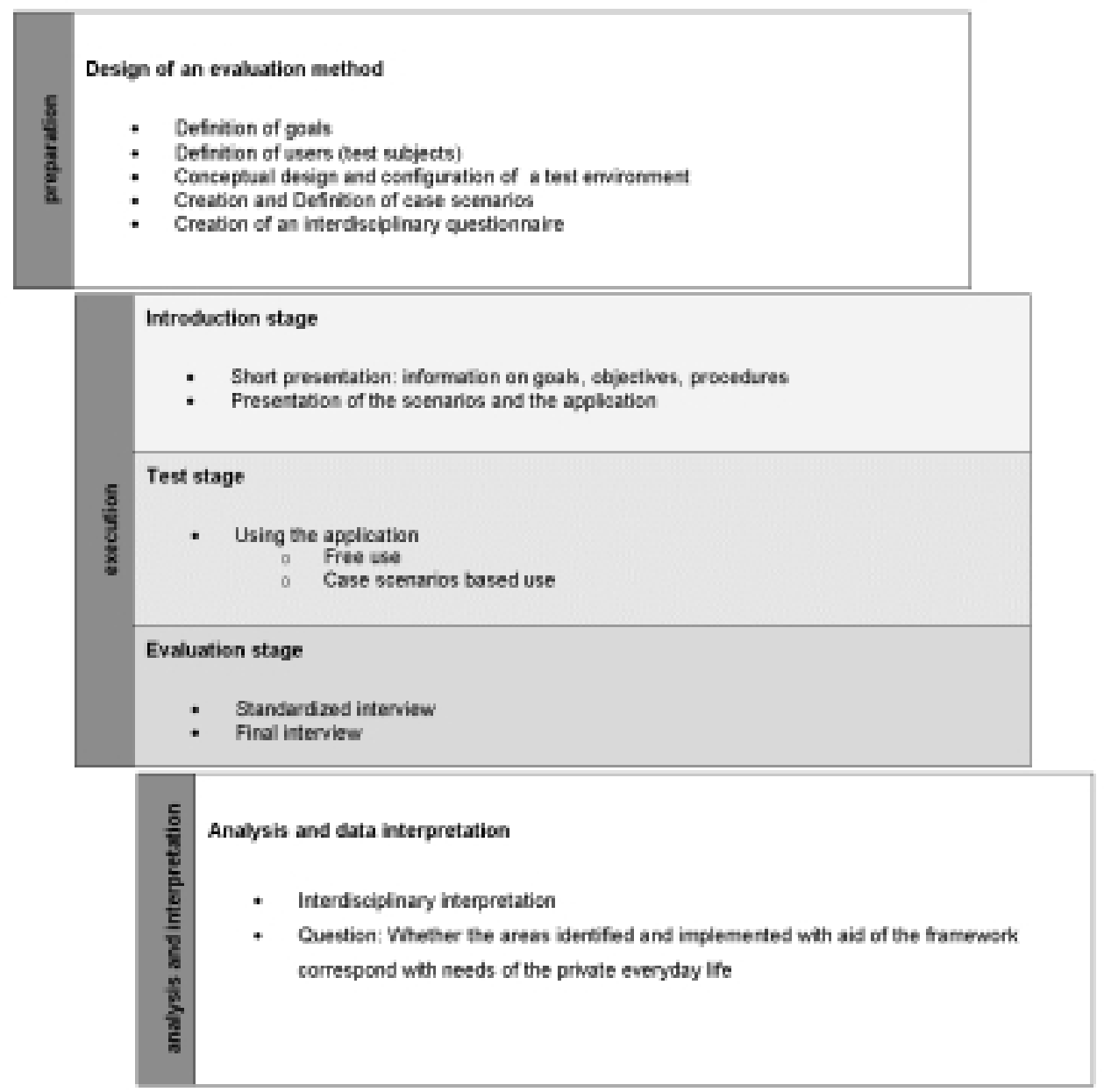

Fig. 8. Evaluation plan.

As illustrated two areas were identified and implemented with aid of the described framework. To evaluate the framework in more detail the implemented applications were integrated into a test environment for evaluating the user behaviour and the user acceptance. This is of high importance, since "the users determine the shape of the technology by their uses and theses specific uses become inputs into the next stage of development" [37]. In the following the evaluation of the area "mobility and orientation" the evaluation method will be described by focussing on the imopo case study. In addition a plan with 3 stages: preparation, execution as well as analysis and interpretation are shown. This plan is illustrated in Fig. 8.

The definition of basic goals and objects was the starting point for the evaluation conducted. It must be made clear, what exactly is supposed to be examined and for which purposes the won data are supposed to be used. Since the success of mobile applications and services in the private area depends on the needs and the acceptance of the users, the central issue of the evaluation should be first, whether mobile services like imopo or MEG can be accepted by the users. In this context the framework have to be evaluated to review the identification of promising areas within the private everyday life. The basic assumptions should be reviewed, confirmed or adapted when required. 


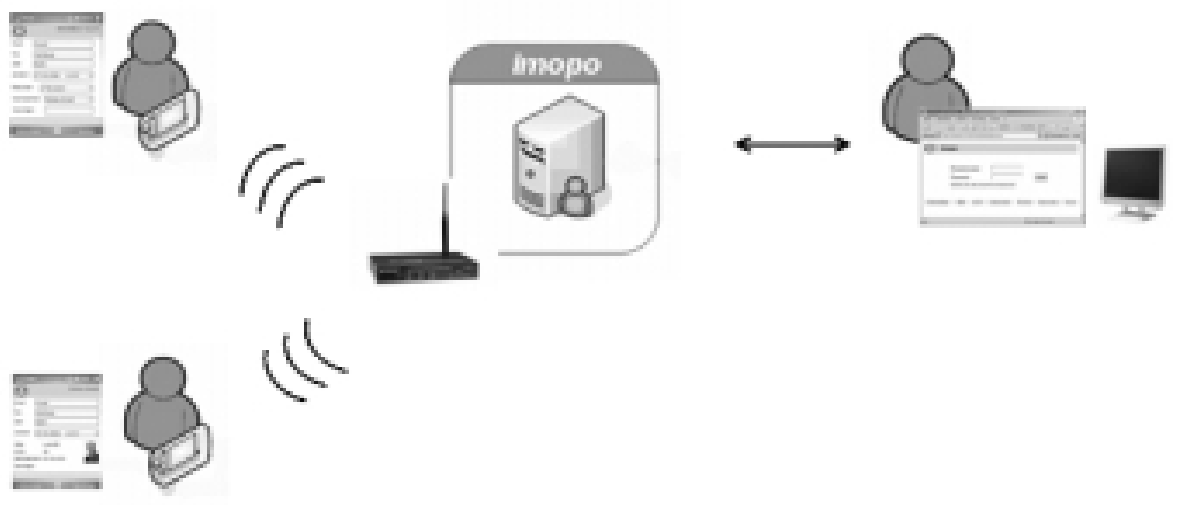

Fig. 9. Simplified composition of the evaluation.

Such an evaluation can basically proceed in a qualitative or quantitative way. It is the main goal of the inquiry to review the previously obtained results and to check if essential points were surveyed or incorrectly estimated. Qualitative and semi-standardized interviews are a suitable instrument to receive information. An essential advantage of this procedure is the ability of the interviewer to make an inquiry in case of misunderstandings and other difficulties. The figure below represents a simplified illustration of the structure of the evaluation, which was conducted by using wireless connected PDAs and stationary Internet terminals.

The question catalogue generated reflects the overall intention. It serves as a guideline to challenge the user side questions and perspectives. In order to obtain this, different categories were determined, which are based of the potentials of mobile technologies: utilization readiness, characteristics of devices $\&$ technical aspects, profiling \& security, payment readiness, convenience. As a time frame, 60 minutes per interviews were planned with two test subjects at a time. The three stages of the execution were organized in an introduction stage, a test stage and an evaluation stage. At first in the introduction stage the test user will be informed about the goals and the objects of the evaluation. In the test stage the test user get shown the use of the application. Based on typical case scenarios they can test the functionalities of the application. Subsequently they can work with the application by themselves. At this time the interviewers adopt the methods of observation and of loudly thinking. Based on the interdisciplinary questionnaire in the evaluation stage the test users will be interviewed afterwards. Finally the results of the evaluation were analysed and summarized.

As an important result, the chosen imopo scenario illustrates that the value of many services depends on a sufficiently large number of consumers. A critical mass of consumers must be reached who are willing to pay for the services offered. In this case, different revenue models are conceivable, e.g. membership fee, package tariffs, advertisement, provisions, transaction-based solutions. From the consumer's perspective it is important that billing models are created transparently. Furthermore, the mobile devices should be as easy to use as possible because high technical barriers could discourage many potential users. The acceptance of complex services depends strongly on the societal development. For example, many elderly people still have problems with how to use cell phones, whereas many younger people are able to use a multitude of technical appliances intuitively. The expertise to deal with technical devices and the acceptance of their use will thus change correspondingly over time. Also the required media competence on the users side, the possibilities to establish trust in the use of user interfaces in mobile as well as ubiquitous environments and in the supplying organisations and the underlying infrastructures and the 
already existing user acceptance are prominent considerations from a social point of view. All things considered, the evaluation process led to results which underlined the impact of the chosen approach and pointed out the relevance of more systematically developed mobile services.

\section{Summary and future prospects}

Recapitulating, it first has to be stated, that scenarios of mobilised private everyday life will gain in importance and an incremental relevance of mobile services is expected for private everyday life. Thus, the creation of future services should be done by incorporating the user's needs.

Furthermore through the increasing linking-up between and within formerly self-contained sectors of business and private everyday live, as well as through the associated appearance of electronic, mobile, and even ubiquitous service scenarios [31] various other changes but also chances arise for the suppliers of services. So it is important to mention, that if an enterprise wants to offer adequate services on the market for private households, the obvious choice is to link several providers of e- and $\mathrm{m}$-services. This means that the key to success for the producer, supplier, and the service provider lies in the ability to work together in the development and offering of easy-to-use services. It can be predicted that alongside singular offered e- and m-services so-called complex services will be developed in future. These can bundle a multitude of formerly singular offered services. For private customers such complex services could lead to an enhanced usability in terms of e.g. standardized user interfaces, as well as to an improved simplicity, for instance through the easier access to formerly singular, distributed services. Prominent examples for such integrated offers which are frequently used by private customers are expedia.com, where travellers can combine formerly separate services, e.g. flights, hotel-bookings, car rentals, and amazon.com, where customers can shop like in a department store. Within this context, the illustrated framework provides options to analyse specific plans of (potential) services providers to introduce mobile as well as complex services to private user segments. It offers basic suggestions for specific and targetoriented analyses. Furthermore, the framework can serve as an instrument for designing the optimised alignment of processes which are in connection with mobile services within the suppliers' organisations. The underlying changes of processes can be measured in a more effective way, especially by using the proposed systematic method to launch and establish complex services in settings of private everyday life. Such a combination of existing services offers chances to develop complex services with innovative processes, e.g. it is conceivable that the private sector will evolve as a partner within new networks [8].

Also the suppliers have to take care of the potentials of mobility described above. The individual activities in the process and the behaviour of the users in his or her private everyday life, especially regarding their spatial, temporal, and action-oriented alignments, have to be analysed in detail. The customers will be supported by a broad spectrum of innovative mobile services. Simultaneously they are the ones defining their expectations and requirements regarding privacy, security, confidence, and other specific demands on acceptable services [39]. According to this, economic developments (e.g. expertise in respect to mobile devices, acceptance for complex services) need to be observed [3]. Furthermore, it is essential that the services offered can be used in varying contexts and, therefore, can be used by means of various devices. Thus these changes have to be analyzed in a systematically way provided by the illustrated framework. In doing so it is important to point out, that the expansion of established and accepted application systems towards mobile services presents a massive challenge for the user as well as for the supplier. Thus, not only changes of current application systems and the habits of the consumers using them, but also the need for an alteration of the business processes on the supplier's side can be predicted. This leads to an essential condition for the successful and broad implementation of innovative 
mobile services in the private everyday life: It is absolutely necessary to create significant benefit for business suppliers and especially for the private consumers.

\section{References}

[1] K. Backhaus, Multivariate Analysemethoden, Springer, Berlin 2006.

[2] O. Bohl, S. Manouchehri and U. Winand, Identification of Alternatives to Support Processes of Everyday Life with Mobile Technologies, in: Proceedings of MoMM 2006, G. Kotsis, D. Taniar, E. Pardede and I.K. Ibrahim, eds, Yogyakarta, Indonesia, Austrian Computer Society, Band 215.

[3] O. Bohl, S. Manouchehri and U. Winand, Towards an Optimised Design of Private Complex Service in: International Journal of Knowledge Management Studies (IJKMS), Special Issue on: Information Technology - Advances in Services, Knowledge and Technology, Inderscience, 2007.

[4] R.N. Bolton and J.H. Drew, A Multistage Model of Customers' Assessments of Service Quality and Value, In: The Journal of Consumer Research 1991 17(4) (Mar.), 375-384.

[5] S. Buse, Der mobile Erfolg, in: E-Business und M-Business, F. Keuper, ed., Wiesbaden 2002, pp. 91-116.

[6] L. Chen and G. Skelton, Mobile Commerce Application Development, Cypertech Publishing, Hershey 2005.

[7] B.S. Everitt, S. Landau and M.L. Everitt, Cluster analysis, Oxford University Press, US 2001.

[8] G.T. Ferguson and T.H. Pike, Mobile Commerce: Cutting Loose - Making a Shift from $\mathrm{m}$ to u, in: Information age economy, H. Buhl, A. Huther and B. Reitwiesner, eds, Physica, Heidelberg 2001, pp. 7-14.

[9] J. Gausemeier and A. Fink, Fuehrung im Wandel, Hanser, Muenchen 1999.

[10] R. Harwig and E. Aarts, Ambient Intelligence: invisible electronics emerging, in: Interconnect Technology Conference, Proceedings of the IEEE 2002 International, pp. 3-5.

[11] H.G. Kemper and E. Wolf, Iterative Process Models for Mobile Application Systems: A Framework, in: Proceedings of the 23. International Conference on Information Systems, Barcelona 2002, pp. 401-413.

[12] L.M. Kolbe, Informationstechnik fuer den privaten Haushalt, Physica, Heidelberg 1998.

[13] A. Kornak, J. Teutloff and M. Welin-Berger, Enterprise Guide to Gaining Business Value from Mobile Technologies, Wiley Publishing, Hoboken 2004.

[14] R. Kraut, T. Mukhopadhyay, J. Szczypula, S. Kiesler and W. Scherlis, Communication and information: alternative uses of the Internet in households, in: Proceedings of the SIGCHI conference on Human factors in computing systems, Addison-Wesley, New York 1998, pp. 368-375.

[15] A. Kuchinsky, C. Pering, M.L. Creech, D. Freeze, B. Serra and J. Gwizdka, FotoFile: A Consumer Multimedia Organization and Retrival System, in: Proceeeding of the CHI 1999, ACM, Pittsburgh, pp. 496-503.

[16] Y.E. Lee and I. Benbasat, A Framework for the Study of Customer Interface Design for Mobile Commerce, in: International Journal of Electronic Commerce 8(3) (Spring 2004), 79-102.

[17] S.M. Lipset and R. Bendix, Social Mobility in Industrial Society, Transaction Publishers, Somerset 1991.

[18] I. Miles, From IT in the home to home informatics, in: Computers in the Human Context: Information Technology, Productivity and People, T. Forester, ed., MIT Press, 1998, pp. 198-212.

[19] A. Monk, User-centered Design: The Home Use Challenge, in: Home informatics and telematics, A. Sloane and F. van Rijn, eds, Kluwer Academic Publishers, Boston 2000, pp. 181-190.

[20] M. Morris, J. Lundell and E. Dishmann, Catalyzing Social Interaction with Ubiquitous Computing: A needs assessment of elders coping with cognitive decline, in: Proceedings of CHI 2004, ACM, Pittsburgh, pp. 1151-1154.

[21] M. Moore and S. Rogaber, Issues in User Interface Migration, in: Proceedings of the Third Software Engineering Research Forum, Orlando 1993.

[22] N. Mundorf, Information Technologies in the Home: Current and Future Trends, in: Dienstleistungen, H.J. Bullinger, ed., Gabler, Wiesbaden 1999, pp. 210-223.

[23] J. O'Brien, T. Rodden, M. Rouncefiled and J.A. Hughes, At home with technology, in: ACM Transactions on ComputerHuman Interaction 6(3) (1999), 282-308.

[24] L. Palen, M. Salzman and E. Youngs, Behavior \& practice of new mobile phone users. in: Proceedings of ACM $2000-$ Conference on Computer Supported Cooperative Work, Philadelphia, pp. 201-210.

[25] P.E. Pedersen and L.B. Methlie, Understanding mobile commerce end-user adoption: a triangulation perspective and suggestions for an exploratory service evaluation framework, in: Proceedings of HICSS-35, Hawaii 2002.

[26] K. Petrova, Mobile Commerce Applications and Adoption, in: Encyclopedia of E-Commerce, E-Government, and Mobile Commerce, M. Khosrow-Pour, ed., Idea Group, Hershey 2006, pp. 766-771.

[27] T.L. Pham, G. Schneider and S. Goose, A Situated Computing Framework for Mobile and Ubiquitous Multimedia Access using Small Screen and Composite Devices, in: Proceedings of the eighth ACM international conference on Multimedia, Marina del Rey 2000, pp. 323-331. 
[28] A.R. Puerta, E. Cheng, T. Ou and J. Min, Mobile: User-Centered Interface Building, in: Human Factors in Computing Systems, CHI 1999, ACM Press, pp. 426-433.

[29] Y. Punie, A social and technological view of Ambient Intelligence in Everyday Life, Key Deliverible - The European Media and Technology in Everyday Life Network, 2000-2003. http://www.lse.ac.uk/collections/EMTEL/reports/ punie_2003_emtel. 2006-06-24.

[30] S. Saha, M. Jamtgaard and J. Villasenor, Bringing the Wireless Internet to Mobile Devices, in: Computer, June 2001, pp. 54-58.

[31] A.K. Salkintzis, The Evolution toward the Mobile Internet, in: Mobile Internet - Enabling Technologies and Services, A.K. Salkintzis, ed., CRC Press, Boca Raton 2004.

[32] A. Sloane and F. van Rijn, Home Informatics and Telematics, Springer, New York 2000.

[33] D. Steinbock, The Mobile Revolution - The making of mobile services worldwide, Kogan Page, London 2005.

[34] C.A. Szabó, Applications and Services to Meet Society-Related Needs, in: Broadband Services - Business Models and Technologies for Community Networks, I. Chlamtac, A. Gumaste and C.A. Szabó, eds, John Wiley \& Sons, West Sussex 2005, pp. 27-46.

[35] F. van Rijn, K. Bjerg and G. Frerk, Perspectives on Home-Oriented Informatics and Telematics, in: Proceedings of the IFIP 12th World Computer Congress on Education and Society, (Vol. 2), North-Holland Publishing, Amsterdam 1992, pp. 494-507.

[36] A. Venkatesh, Computers and Other Interactive Technologies for the Home, in: Communications of the ACM 39(12) (1996), 47-54.

[37] A. Venkatesh and F. Nicosia, New Technologies for the Home-Development of a Theoretical Model of Household Adoption and Use, in: Advances in Consumer Research, (Vol. XXIV), M. Brucks and D. MacInnis, eds, 1997, pp. 522528.

[38] J. Vesa, Mobile Services in the Networked Economy, IRM Press, Hershey 2005.

[39] U. Winand, R. Gillner and T. Sommerlatte, Electronic/Mobile Private Services, in: Wirtschaftsinformatik 2005, Ferstl, ed., Physica, Heidelberg.

[40] P. Zoche et al., Virtuelle Mobilitaet, Springer Verlag, Berlin 2002.

Oliver Bohl received his $\mathrm{PhD}$ in Economics from the University of Kassel in 2006. He is currently an Assistant Professor at the Institute for Information Systems at the University of Kassel, Germany. Furthermore he works a project manager and senior researcher at the Research Centre for the Design of Information Systems, Kassel. His current research interest includes aspects of mobile service creation, social mobile software, and knowledge/learning management.

Shakib Manouchehri is a researcher at the Research Centre for the Design of Information Systems, Kassel. He is also a Doctoral Candidate at the Institute for Information Systems, University of Kassel, Germany. His current research focuses on business process management, information and communication management, corporate knowledge management, social software, and mobile service creation.

Udo Winand received his $\mathrm{PhD}$ in Economics from the University of Cologne in 1976. He is currently a Full Professor at University of Kassel and Head of the Institute for Information Systems as well as Head of the Research Centre for the Design of Information Systems, Kassel. His current research focuses on business networks and partnerships, virtual organisations, eB2C business, trust in information systems, knowledge management and eLearning. Prof. Winand is Manager in Chief of the Working Group Managerial Partnership of the Schmalenbach Society, German Society for Management. He is (co-)editor of several journals and series of books 

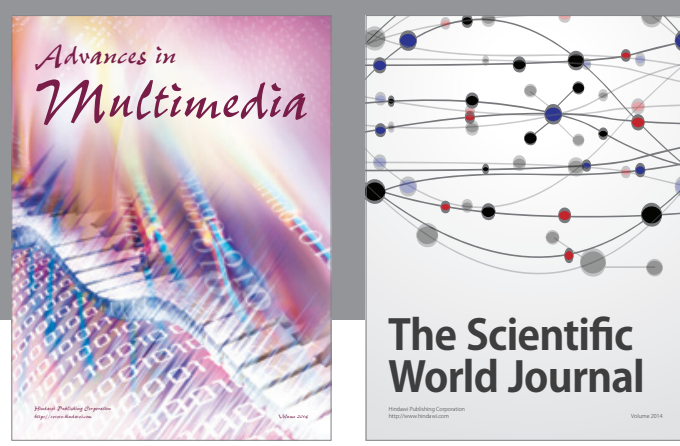

The Scientific World Journal
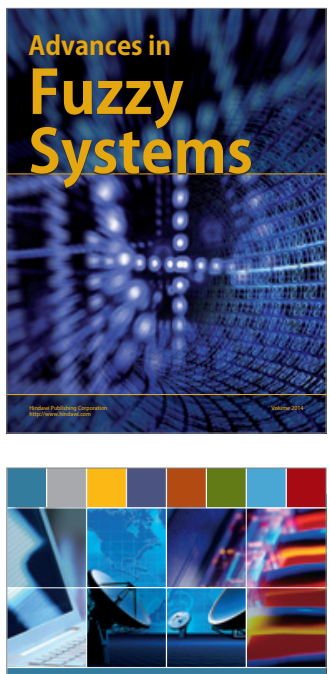

Computer Networks and Communications
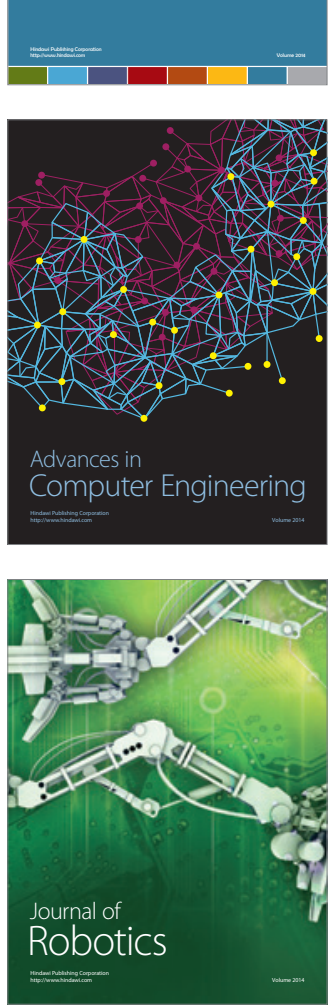
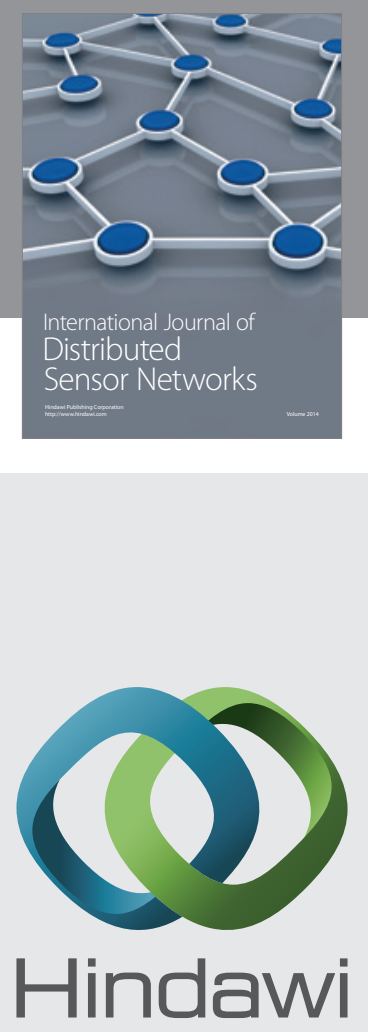

Submit your manuscripts at

http://www.hindawi.com
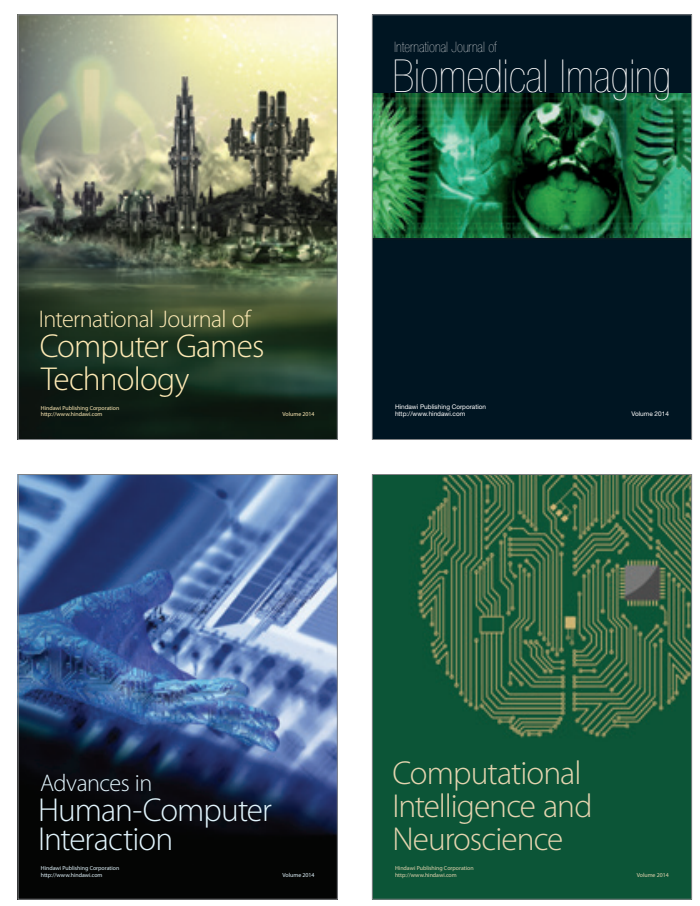
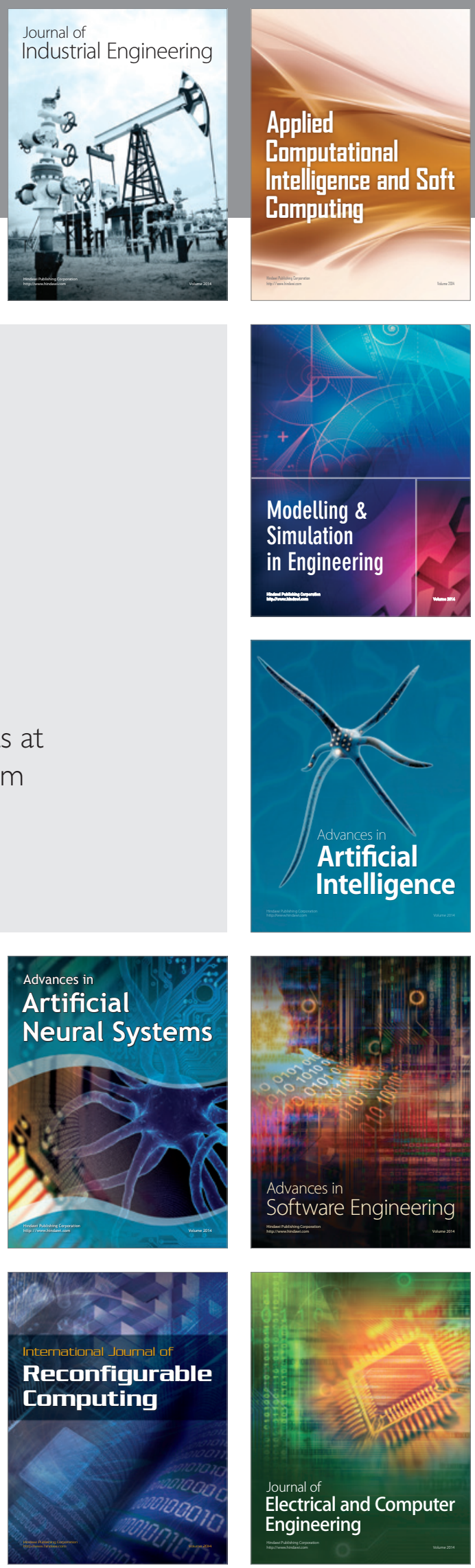